AperTO - Archivio Istituzionale Open Access dell'Università di Torino

\title{
Ligand stabilization and effect on unfolding by polymorphism in human flavin-containing
} monooxygenase 3

\section{This is a pre print version of the following article:}

Original Citation:

Availability:

This version is available http://hdl.handle.net/2318/1769394

since 2021-01-27T12:07:59Z

Published version:

DOI:10.1016/j.ijbiomac.2020.08.032

Terms of use:

Open Access

Anyone can freely access the full text of works made available as "Open Access". Works made available under a Creative Commons license can be used according to the terms and conditions of said license. Use of all other works requires consent of the right holder (author or publisher) if not exempted from copyright protection by the applicable law. 


\title{
Ligand stabilization and effect on unfolding
}

\section{by polymorphism in human flavin-containing monooxygenase 3}

\author{
G. Catucci, D. Aramini, S.J. Sadeghi and G. Gilardi*
}

Department of Life Sciences and Systems Biology, University of Torino, Italy.

*Corresponding author:

Gianfranco Gilardi, email address: gianfranco.gilardi@unito.it

Keywords: unfolding, SNP, calorimetry 


\section{Abstract}

Pharmacogenomics is a powerful tool to prevent adverse reactions caused by different response of individuals to drug administration. Single nucleotide polymorphisms (SNPs) represent up to $90 \%$ of genetic variations among individuals. Drug metabolizing enzymes are highly polymorphic therefore the kinetic parameters of their catalytic reactions can be significantly influenced. This work reports on the unfolding process of a phase I drug metabolizing enzyme, human flavin-containing monooxygenase 3 (hFMO3) and its single nucleotide polymorphic variants (SNPs) V257M, E158K and E308G. Differential scanning calorimetry (DSC) indicates that the thermal denaturation of the enzyme is irreversible. The melting temperature $\left(\mathrm{T}_{\mathrm{m}}\right)$ for the (Wild Type) WT and its polymorphic variants is found to be in a range from $46{ }^{\circ} \mathrm{C}$ to $50{ }^{\circ} \mathrm{C}$. Also the activation energies of unfolding $\left(E_{a}\right)$ show no significant differences among all proteins investigated (290-328 KJ/mol), except for the E308G variant that showed a significantly higher $E_{a}$ of $412 \mathrm{KJ} / \mathrm{mol}$. The presence of the bound $\mathrm{NADP}^{+}$cofactor is found to stabilize all the variants by shifting the main $\mathrm{T}_{\mathrm{m}}$ by $4-5^{\circ} \mathrm{C}$ for all the proteins, exception made for $\mathrm{E} 308 \mathrm{G}$ where no changes are observed.

Isothermal titration calorimetry (ITC) was used to characterize the interaction of the protein with $\mathrm{NADP}^{+}$ in terms of dissociation constant $\left(\mathrm{K}_{\mathrm{d}}\right)$, enthalpy $(\Delta \mathrm{H})$ and entropy $(\Delta \mathrm{S})$. $\mathrm{K}_{\mathrm{d}}$ values of 1.6 and $0.7 \mu \mathrm{M}, \Delta \mathrm{H}$ of $-13.9 \mathrm{Kcal} / \mathrm{mol}$ and $-16.8 \mathrm{Kcal} / \mathrm{mol}, \Delta \mathrm{S}$ of $-20.5 \mathrm{cal} / \mathrm{mol} / \mathrm{deg}$, and $-28.5 \mathrm{cal} / \mathrm{mol} / \mathrm{deg}$ were found for V257M and E158K respectively. E308G was found to be unable to bind the $\mathrm{NADP}^{+}$cofactor, a result that is in line with the $\mathrm{T}_{\mathrm{m}}$ results. Circular dichroism also confirmed an overall lower stability of E308G, while $\mathrm{NADP}^{+}$was found to give a strong positive shift of the $\mathrm{T}_{\mathrm{m}}$ stabilizing the structure of E158K (46.2 to $\left.50.6^{\circ} \mathrm{C}\right)$.

Previous data highlighted significant differences in terms of activity among the SNPs of hFMO3. In this work a minor impact of the SNPs was found on the stability of the enzyme in the ligand free form, except for $\mathrm{E} 308 \mathrm{G}$, whereas the binding of $\mathrm{NADP}^{+}$reveals major differences among WT and polymorphic 
variants that are all measurable in terms of heat capacity, enthalpy and secondary structure content. These data provide the first direct evidence of ligand stabilization effects on hFMO3 that can explain the differences observed in catalytic efficiencies and serve as the starting point for the development of inhibitors of this enzyme. 


\section{Introduction}

Human flavin-containing monooxygenases (hFMOs) comprise a family of five iso-enzymes and are the second most important phase 1 drug-metabolizing enzymes after cytochromes P450 [1-3]. Its isoform 3 (hFMO3) is predominantly expressed in the liver where substrates containing nitrogen-, sulphur- and phosphorous-containing soft nucleophiles [4-12] are transformed into more polar and excretable metabolites [13-18].

Wild type hFMO3 contributes to the metabolism of several important drugs [19] such as ranitidine, cimetidine, tamoxifen, clozapine, benzydamine. The hFMO3 gene contains many single SNPs and several studies have demonstrated that these mutations can severely affect the activity of the enzyme resulting in lower or abolished activity [7, 20-25]. A recent work for example revealed that the variations in plasma concentrations of the metabolites of tamoxifen, a well-known antiestrogenic drug used in the treatment of breast cancer, can be ascribed to the SNPs of cytochromes P450, FMO3 and sulfotransferases [26]. Another recent work showed that FMO3 E158K/E308G decreased the plasma concentration of voriconazole through its higher metabolic activity [27]. Genetic polymorphisms of FMO3 could also affect the pharmacokinetics of sulindac in women who undergo preterm labor [28]. Single nucleotide polymorphisms can dramatically impact both substrate affinity and catalytic activity. We have previously shown how the hFMO3 N61S active site mutation can lead to a 100 fold decrease of $\mathrm{k}_{\mathrm{cat}} / \mathrm{K}_{\mathrm{m}}$ for tamoxifen [29]. In another work we have also reported how SNPs located on the surface of the protein structure can either increase (E158K) or decrease (V257M) the catalytic efficiency for tamoxifen. Futhermore, hFMO3 is also the only enzyme in the human body responsible for the transformation of trimethylamine (TMA) to trimethylamine N-oxide (TMAO) metabolite [30] and recently this metabolite was found to be associated to atherosclerosis [31]. It was reported that TMAO binds to PERK at physiologically relevant concentrations and selectively activates the PERK branch of the unfolded protein response inducing the transcription factor FoxO1, a key driver of metabolic disease, 
in a PERK-dependent manner [32]. Trimethylaminuria (TMAU) is a genetic disease associated to a SNP of FMO3 that is unable to oxidize TMA [33]. TMAU is also known as the "fish-odor syndrome" due to the pungent smell of breath, sweat and urines of the patients caused by the accumulation of TMA. Up to this date the precise mechanism underlying differences in activity for the SNP of hFMO3 has not been revealed. Biophysical studies were carried out on hFMO3 aimed at understanding the influence of temperature on the FMO activity [34-36]. The present study aims at understanding the unfolding process of hFMO3, thus tackling the problem from a structural perspective, providing information on the stability and $\mathrm{NADP}^{+}$binding properties alterations due to common SNPs. As the crystal structure of hFMO3 is not available at present, molecular modelling and docking simulations [37-40] combined with biophysical methodologies such as differential scanning calorimetry (DSC) can be used to shed light on this process. DSC is a powerful technique that can help providing biophysical insights about a specific protein by measuring the heat capacity of states and the excess heat induced by temperature change [41] [42]. Recently we have published the inactivation mechanism of hFMO3 comparing WT enzyme to an active site mutant (N61S) that abolishes its activity and provides preliminary evidence of the role of $\mathrm{NADP}^{+}$in structure stabilization [29]. In the present work differential scanning calorimetry (DSC) is used to investigate the details the stability of hFMO3 polymorphic mutants and the kinetic nature of the denaturation process of V257M, E158K and E308G. Furthermore, the addition of $\mathrm{NADP}^{+}$is used to assess binding properties and changes in the energetics components upon stabilization of the protein structure. Characterization of the binding properties of the enzyme is performed using Isothermal Titration Calorimetry (ITC). We have recently developed a method for measuring the turnover of substrates of hFMO3 by ITC [43]. Here the ITC measurements are used to confirm the differences of the polymorphic variants in binding the $\mathrm{NADP}^{+}$cofactor and provide the dissociation constants and energetics involved in the binding reaction. Finally, Circular Dichroism (CD) is employed to explain the 
effect of the mutations in both secondary structure and ligand induced stabilization of the enzyme leading to a comprehensive analysis of the unfolding mechanism of hFMO3 and $\mathrm{NADP}^{+}$binding properties.

\section{Materials and Methods}

\subsection{Expression and purification of hFMO3 polymorphic variants}

All steps of expression and purification were performed according to previously published protocols [44]. Wild type and polymorphic variants were expressed in E. coli JM109 cells and grown 24 h postinduction. Proteins were purified via Ni affinity chromatography. Spectra of the eluted fractions (with $40 \mathrm{mM}$ histidine) were recorded using a diode array HP-8453E spectrophotometer. FAD containing fractions with the characteristic absorption peaks at 375 and $450 \mathrm{~nm}$ were pooled and exchanged to storage buffer (100 mM potassium phosphate buffer $\mathrm{pH} 7.4,20 \%$ glycerol and $1 \mathrm{mM}$ EDTA) by $30 \mathrm{kDa}$ cutoff Amicon membranes and stored at $-20^{\circ} \mathrm{C}$.

\subsection{Differential scanning calorimetry}

The DSC experiments were done using VP-Capillary DSC, Malvern Instruments Ltd Worcestershire, UK. The samples were placed in the calorimeter in a $200-\mu 1$ sample cell against a $200-\mu 1-\mathrm{ml}$ reference cell that was filled blank solution consisting of the protein containing buffer: $50 \mathrm{mM} \mathrm{Kpi} \mathrm{pH} \mathrm{7.4.} \mathrm{The}$ cells were equilibrated inside the calorimeter for 10 minutes at $25^{\circ} \mathrm{C}[29,45]$ before heating up to the final temperature at a given rate. Cycles of cooling and reheating of the samples were performed to obtain the background for buffer subtraction or test hypothetical refolding. Replicate runs did not vary more than $0.25^{\circ} \mathrm{C}$. The denaturation temperature $\mathrm{T}_{\mathrm{m}}$ and the $\Delta \mathrm{H}$ was determined by fitting the data with the ORIGIN embedded program suite. In order to perform the analysis at different scan rates the cells were pre-equilibrated with at least 10 cycles of buffer in the same setup of the experiment. Protein 
concentration was $10 \mathrm{uM}$ in all experiments. All experiments were conducted in $50 \mathrm{mM} \mathrm{Kpi} \mathrm{pH} 7.4$ with a dilution factor of the storage buffer of $10^{\wedge}$.

\subsection{Activation energy of unfolding}

Calculation for the activation energy of unfolding was performed using the mathematical model previously described by Sanchez-Ruiz in 1988 [46]. In this model the temperature value corresponding to the maximum of the heat capacity curve, $\mathrm{T}_{\mathrm{m}}$, changes with heating rate $v$ according to $\ln \left(\frac{v}{T_{m}^{2}}\right)=\ln \left(\frac{A R}{E_{a}}\right)-\frac{E_{a}}{R T_{m}}(1)$ where $A\left(\mathrm{~min}^{-1}\right)$ is the frequency factor, $E_{a}\left(\mathrm{~kJ} \mathrm{~mol}^{-1}\right)$ is the activation energy for the denaturation step, and $R$ the gas constant. It follows that the slope of the plot of $\ln \left(\frac{A R}{E_{a}}\right)$ as a function of $1 / \mathrm{T}_{\mathrm{m}}$ equals $\frac{E_{a}}{R}$.

\subsection{Circular dichroism analysis}

Experiments were performed by using Jasco-815 instrument (Jasco Instruments). Thermal denaturation experiments were performed by raising the temperature from $25^{\circ} \mathrm{C}$ to $65^{\circ} \mathrm{C}$ using a Peltier thermo block (PTC-348 WI Peltier block) and allowing the protein sample $(2 \mu \mathrm{M})$ to equilibrate for 5 minutes at each temperature before recording the spectrum. The spectra were collected by taking 10 accumulations (ten spectra combined in a single signal). All experiments were conducted in $50 \mathrm{mM} \mathrm{Kpi} \mathrm{pH} 7.4$ with a dilution factor of the storage buffer of $10^{\wedge}$.

\subsection{Secondary structure calculation}

For each sample three replicates were performed and the resulting CD signal at $222 \mathrm{~nm}$ was plotted as function of temperature. The data were fitted to a single step transition curve in order to calculate the melting temperature $\left(\mathrm{T}_{\mathrm{m}}\right)$. The data were plotted in SigmaPlot using the ellipticity [47, 48] values as 
function of temperature. Fitting was carried out by using the ellipticity of the fully folded protein at $25^{\circ} \mathrm{C}$ and fully unfolded protein at $65^{\circ} \mathrm{C}$. $\mathrm{CD}$ analysis was also be performed in presence of $0.5 \mathrm{mM} \mathrm{NADP}$.

\subsection{Isothermal titration calorimetry}

Isothermal titration calorimetry (ITC) experiments were conducted in a ITC-200, Malvern Instruments Ltd Worcestershire, UK as described previously with minor modifications [29, 49]. The calorimeter contains a $200-\mu 1$ reference cell, a $200-\mu 1$ sample cell and a $40-\mu 1$ syringe for injections. The reference cell was filled with milliq pure water. The other cell was filled with $10 \mu \mathrm{M}$ of the sample. The cells were brought to the experimental temperature by equilibrating for 10 min at a $\Delta \mathrm{P}$ value of 10 . Injections were then performed at a temperature of $25^{\circ} \mathrm{C}$ with a 150 second time interval using the "mid feedback" mode and an injection volume of $1 \mu \mathrm{L}$. The first injection was performed with a volume of $0.1 \mu \mathrm{L}$ [50]. All experiments were conducted in $50 \mathrm{mM} \mathrm{Kpi} \mathrm{pH} 7.4$ [51] with a dilution factor of the storage buffer of $10^{\wedge}$. The ligand was dissolved in the flow-through resulting from the last round of exchange.

\section{Results}

\subsection{Scan-rate dependent differential scanning calorimetry analysis}

To better understand how polymorphism affects the stability of hFMO3 the impact of the mutations (V257M, E158K, E308G) was first studied by differential scanning calorimetry (DSC). In a typical DSC experiment the reference cell is filled with buffer, whereas the enzyme is placed in the sample cell; the temperature is then raised linearly to a final value with a fixed velocity (the scan-rate). The results obtained are shown in figure 1.

Figure 1A shows typical thermograms of the WT collected at scan rates ranging between $18^{\circ} \mathrm{C} / \mathrm{h}$ and $180^{\circ} \mathrm{C} / \mathrm{h}$. It can be seen that lower scan rates result in noisier thermograms than higher scan rates, due to 
the inevitable fluctuations occurring for longer permanence at the given temperature. This can be observed for all samples (figure 1B-D for V257M, E158K and E308G respectively). Deconvolution analysis of the thermograms of figure 1 clearly shows the presence of two peaks (figure 2A-D), each characterized by $\mathrm{T}_{\mathrm{m}}$ and $\Delta \mathrm{H}$ values that have been calculated at different scan rates as reported in figure 3. A similar behavior, comprising two transitions with different $T_{m}$ and $\Delta H$ values, can also be observed for the polymorphic variants V257M, E158K, and E308G (Figures 1-3). However, as figure 1 and 3 show their presence and thermodynamic parameters show a different pattern when studied as a function of scan rate.

In all cases the unfolding process was found to be irreversible since re-scan of the protein solution did not result in re-folding of the enzyme [29]. The two transitions in the DSC experiment imply the existence of two populations in the cell which can be interpreted using two different models.

The first model (model 1) invokes the presence of two domains that denature under distinct conditions [52]. This is in line with the results of homologous protein modelling results that showed FMO as a twodomain protein [53-56]. Therefore model 1 would assign the two DSC transitions to the FAD binding domain and the $\mathrm{NADP}^{+}$binding domain. The second model (model 2) entails that the peak at higher temperature is deriving from the unfolding of the protein that actually aggregates and cannot refold. As shown by the results of figure 1 and figure 3 three major phenomena can be observed: 1) the peak temperature of both peaks decreases with decreasing heating rate 2) the enthalpy of the first transitions decreases with decreasing heating rate 3) the enthalpy of the second transition increases or decreases depending on the variant examined. These observations indicate that peak 2 is produced during the unfolding process at the expense of peak 1. In this line of thought, the two transitions do not represent two domains of the enzyme, but they are derived by the unfolding and aggregation process invoked by model 2. This model involves a three-state process in which the final unfolded state is reached after an irreversible transition originating from an aggregated intermediate. 
Further analysis of the DSC data obtained at different scan-rates allows the calculation of the kinetics involved in the unfolding process characterized by the Activation Energy $\left(E_{a}\right)$. To calculate the $E_{a}$ we used the model developed by Sanchez-Ruiz et al. 1988 [46], that requires a linear dependence between the scan-rate and the recorded melting temperature. This trend was indeed found for Peak 1, whilst Peak 2 was not included in the analysis as it represents the aggregated protein derived from Peak 1 . The $E_{a}$ calculated for WT, V2257M, E158K and E308G are 290, 312, 328 and $412 \mathrm{KJ} / \mathrm{mol}$ respectively. All values are reasonably within the range of those found for the denaturation of globular proteins $[57,58]$. Comparison across the data shows that the $E_{a}$ values for V257M and E158K are close to that of the WT, whereas E308G is an outlier with higher $E_{a}$. This peculiarity found for E308G can be explained by the higher propensity of this variant to form aggregates during the unfolding process, as also shown in Figures $2 \mathrm{D}$ and $3 \mathrm{G}$ as the protein population associated to Peak 2.

\subsection{Differential scanning calorimetry analysis in the presence of NADP ${ }^{+}$}

hFMO3 is known to be reduced by its physiological electron donor NADPH. During the enzyme catalytic cycle, NADPH is consumed, then the reduced enzyme binds molecular oxygen to form a C4ahydroperoxy intermediate of the flavin responsible for the oxygenation of the substrate with the concomitant release of a water molecule [59-61]. During these steps $\mathrm{NADP}^{+}$remains bound in the active site leaving only when the catalytic cycle is completed. For this reason, we focused our attention on $\mathrm{NADP}^{+}$that is the ligand present in the active site when the enzyme acts on the substrate. hFMO3 polymorphic variants $(10 \mathrm{uM})$ were incubated with a large excess of $\mathrm{NADP}^{+}(0.5 \mathrm{mM})$ and the DSC thermograms were collected and analyzed (Figure 4) in relation to the WT [29]. A scan-rate of $30^{\circ} \mathrm{C} / \mathrm{h}$ was chosen to better resolve the stabilization effect of the ligand on hFMO3 structure.

Figure 4 shows a general trend in which $\mathrm{NADP}^{+}$increases the $\mathrm{T}_{\mathrm{m}}$ and $\Delta \mathrm{H}$ of all the hFMO3 samples. The shift in the $T_{m}$ is accompanied by an increase in enthalpy due to the creation of bonds between the 
$\mathrm{NADP}^{+}$and the active site of the enzyme. This phenomenon is even more evident for the peak at higher $T_{m}$ that represents the aggregated form of the enzyme formed during unfolding that is probably more open to the solvent and accessible for the cofactor. Similarly to the ligand free condition, also E158K behaves like the wild type enzyme [29] showing stabilization upon ligand binding and a shift to $47.7^{\circ} \mathrm{C}$. V257M is also stabilized by the NADP ${ }^{+}$exhibiting a shift to $47.5^{\circ} \mathrm{C}$. However, it is clear that E308G is not affected by the presence of the ligand and only a minimal increase in $\Delta \mathrm{H}$ is detected.

\subsection{Isothermal titration calorimetry of NADP ${ }^{+}$}

Isothermal titration calorimetry is a technique particularly suited to understand and quantify not only the affinity of a ligand for its binding site, but also the energetics that are involved in the binding event. $\mathrm{NADP}^{+}$was therefore titrated into $\mathrm{WT}$ hFMO3 and its polymorphic variants until saturation was reached. The results are shown in Figure 5.

We previously reported the characterization of $\mathrm{NADP}^{+}$binding to WT hFMO3 [29]. The results showed a $\mathrm{K}_{\mathrm{d}}$ of $3.7 \mu \mathrm{M}$ for $\mathrm{NADP}^{+}$, a $\Delta \mathrm{H}$ of $-25 \mathrm{kcal} / \mathrm{mol}$ and $\Delta \mathrm{S}$ of $-60.9 \mathrm{cal} / \mathrm{mol} / \mathrm{deg}$ [29]. Here figure $5 \mathrm{~A}-\mathrm{C}$ shows the results obtained under the same conditions for V257M, E158K and E308G. Clearly E308G does not show any NADP ${ }^{+}$binding.

On the other hand a full thermodynamic characterization $(\Delta \mathrm{H}, \Delta \mathrm{S}$ and $\Delta \mathrm{G})$ was possible for the other proteins as shown in figure 5D, as well as binding constant values $(\mathrm{kd})$ of 3.7, 1.6 and $0.7 \mathrm{uM}$ for WT, V257M and E158K respectively. Analysis of the thermodynamic parameters shows that the enthalpic component involved in the binding mechanism is substantial, while the positive $-\mathrm{T} \Delta \mathrm{S}$ indicates a possible conformational change responsible for the low $\Delta \mathrm{G}$ values.

It is reasonable to expect that the interaction between $\mathrm{hFMO} 3$ and $\mathrm{NADP}^{+}$occurs upon formation of hydrogen bonds as suggested the enthalpic component, but the binding most probably also causes the exposure of hydrophobic residues to the solvent responsible for the entropic effect. When comparing 
$\mathrm{NADP}^{+}$binding parameters of WT [29], V257M and E158K, the data show that although the affinity for $\mathrm{NADP}^{+}$are not substantially different, $\Delta \mathrm{H}$ appears to be the a key element in the binding process, with a more modest contribution in the mutants. The ITC data are in line with the DSC ones, as both set of data show a higher propensity of WT [29] and E158K to be stabilized by the presence of $\mathrm{NADP}^{+}$. On the other hand $\mathrm{NADP}^{+}$binding was not detected for $\mathrm{E} 308 \mathrm{G}$, a result that is in line with the marginal influence shown by the addition of $\mathrm{NADP}^{+}$in the DSC experiment.

\subsection{Heat-induced changes in the secondary structure in the presence and absence of NADP ${ }^{+}$}

DSC and ITC in combination with CD spectroscopy can help to understand the processes that involved in the unfolding of a protein. Here $\mathrm{CD}$ was used to measure the effect of temperature on the secondary structure of hFMO3 adjusting the scans of the temperature in a directly comparable way to those used to the DSC thermograms [62]. Figure 6 shows the plot of the ellipticity at $222 \mathrm{~nm}$ as a function of temperature allowing to monitor the signal of the alpha helices during the denaturation process at a scan rate of $30^{\circ} \mathrm{C} / \mathrm{h}$. In all cases the data show a one step transition centered around $46-48^{\circ} \mathrm{C}$. All the polymorphic variants exhibit a similar behavior to the WT protein and their stability is only marginally affected by the mutations. Also for the $\mathrm{CD}$ experiments no reversibility in the denaturation process was detected in line with the DSC data [29].

In another set of experiments the mutants were incubated with an excess of $\operatorname{NADP}^{+}(0.5 \mathrm{mM})$ and the difference in terms of $\mathrm{CD}$ signal at $222 \mathrm{~nm}$ was monitored as a function of temperature. The $\mathrm{NADP}^{+}$was found to give a positive shift in the $\mathrm{T}_{\mathrm{m}}$ indicating a stabilization of the proteins. Also for $\mathrm{CD}$, only one transition is present for all the polymorphic variants. As shown in Table 1, the shift in the $\mathrm{T}_{\mathrm{m}}$ is significant only for WT, V257M and E158K. Very little change is observed for E308G, in line with the lack of binding found by ITC. Furthermore when the difference in terms of ellipticity due to $\mathrm{NADP}^{+}$binding is plotted as a function of temperature the data indicates that WT and V257M show a delayed loss of alpha 
helices, as demonstrated by the persistence of the signal at $222 \mathrm{~nm}$ above $50^{\circ} \mathrm{C}$, whereas $\mathrm{E} 158 \mathrm{~K}$ also conserved the content in alpha helices at higher temperatures to a lower extent (figure 7A-C). These data are in line with both DSC and ITC data that showed the same trend for both WT and polymorphic variants. Interestingly also this analysis confirms the fact that E308G does not seem to be significantly affected in terms of stabilization by $\mathrm{NADP}^{+}$(figure 7D).

\section{Discussion}

The aim of this work is to show how small structural differences, encoded by SNPs, can impact the folding and the stability of the enzyme. Here, the denaturation of hFMO3 and the role of $\mathrm{NADP}^{+}$in stabilizing its structure are studied using differential scanning calorimetry, isothermal titration calorimetry and circular dichroism. DSC reveals that unfolding of hFMO3 is irreversible [29]. WT and polymorphic variants do not exhibit significant differences in unfolding experiments in the absence of $\mathrm{NADP}^{+}$. The denaturation of hFMO3 consists in a 3 step process. The final unfolded state is reached through an irreversible transition originating from an aggregated intermediate that is revealed in the thermogram as the second of the two peaks. The process is kinetically controlled as shown by the heating rate dependence. During unfolding the aggregated form of the enzyme is present in different ratios for the polymorphic variants. Moreover E308G significantly differs from the other variants in terms of activation energy of unfolding. Indeed for this mutant unfolding yielded a higher ratio of aggregation. Incubation of WT and polymorphic hFMO3 with a large excess of $\mathrm{NADP}^{+}$results in modified thermograms. $\mathrm{NADP}^{+}$stabilizes the structure of hFMO3 by interacting with both populations of the enzyme that show both a shift to a higher $\mathrm{T}_{\mathrm{m}}$ and an increase in the $\Delta \mathrm{H}$. Wild type enzyme shows higher stabilization upon binding to $\mathrm{NADP}^{+}$and also in this case $\mathrm{E} 308 \mathrm{G}$ is only slightly affected by the presence of the ligand. 
$\mathrm{NADP}^{+}$was titrated into the hFMO3 enzyme solutions using isothermal titration calorimetry until saturation of the enzyme was reached and the results highlight important characteristics in the binding properties of the variants. WT, V257M and E158K show similar $\mathrm{K}_{d}$ values $(3.7,1.6$ and $0.7 \mu \mathrm{M}$ respectively), whereas for E308G no binding is detected. The analysis of the energetics involved in the binding of $\mathrm{NADP}^{+}$shows that the enthalpic is the strongest component of the $\Delta \mathrm{G}$ and that $-\mathrm{T} \Delta \mathrm{S}$ drives against the $\Delta \mathrm{G}$ indicating a possible conformational change. It is plausible that the interaction between hFMO3 and $\mathrm{NADP}^{+}$occurs upon formation of hydrogen bonds, but the binding also causes the exposure of hydrophobic residues to the solvent that are responsible for the entropic effect. The enthalpic factor is a key element in the binding of $\mathrm{NADP}^{+} \mathrm{hFMO} 3$ and the variants show a diminished ability in complexing with the cofactor as shown by both DSC and ITC.

Circular dichroism shows that the unfolding process followed through the signal of the alpha helices can only be fit to a single transition. The same stability trend among the variants, in terms of $\mathrm{T}_{\mathrm{m}}$, is also present in $\mathrm{CD}$. Moreover $\mathrm{CD}$ confirms that $\mathrm{NADP}^{+}$stabilizes the structure of hFMO3 as shown by a positive shift in the $\mathrm{T}_{\mathrm{m}}$. The shift in the $\mathrm{T}_{\mathrm{m}}$ is large only in the case of WT and E158K hFMO3, whereas minor change are detected in the case of V257M and for E308G no change was observed.

\section{Conclusion}

This work provides the first detailed evidences for the effect of SNPs on the structural stability of hFMO3. The data highlight also the stabilizing effect and the energetics involved in the binding of $\mathrm{NADP}^{+}$. The biophysical characterization of both $\mathrm{NADP}^{+}$free and $\mathrm{NADP}^{+}$bound hFMO3 can serve as a starting point in the development of an inhibitor of hFMO3 that could mimic the binding of NADP $^{+}$ with potential therapeutic use for the reduction of circulating TMAO levels that are associated to atherosclerosis [31]. In order to use this type of inhibitor as a therapeutic agent the molecule shouldn't 
completely abolish hFMO3 activity because high levels of TMA in sweat and urines would be a detrimental side effect.

Furthermore, the overall biophysical approach of this work can be extended to other enzymes with promiscuous binding pockets to understand the effect of SNPs on the structure-function relationship that are not immediately detectable by typical assays that are focused on affinity or activity for a specific substrate. 


\section{References}

[1] S.K. Krueger, J.E. VanDyke, D.E. Williams, R.N. Hines, The role of flavin-containing monooxygenase (FMO) in the metabolism of tamoxifen and other tertiary amines, Drug Metabolism Reviews. 38 (2006) 139-147. https://doi.org/10.1080/03602530600569919.

[2] J.R. Cashman, The implications of polymorphisms in mammalian flavin-containing monoloxygenases in drug discovery and development, Drug Discovery Today. 9 (2004) 574-581. https://doi.org/10.1016/s1359-6446(04)03136-8.

[3] J.R. Cashman, Some distinctions between flavin-containing and cytochrome P450 monooxygenases, Biochemical and Biophysical Research Communications. 338 (2005) 599-604. https://doi.org/10.1016/j.bbrc.2005.08.009.

[4] I.R. Phillips, C.T. Dolphin, P. Clair, M.R. Hadley, A.J. Hutt, R.R. McCombie, R.L. Smith, E.A. Shephard, The molecular-biology of the flavin-containing monooxygenases of man, Chemico-Biological Interactions. 96 (1995) 17-32. https://doi.org/10.1016/0009-2797(94)03580-2.

[5] Y.M. Kim, D.M. Ziegler, Size limits of thiocarbamides accepted as substrates by human flavin-containing monooxygenase 1, Drug Metabolism and Disposition. 28 (2000) 1003-1006.

[6] S.K. Krueger, D.E. Williams, Mammalian flavin-containing monooxygenases: structure/function, genetic polymorphisms and role in drug metabolism, Pharmacology \& Therapeutics. 106 (2005) 357-387. https://doi.org/10.1016/j.pharmthera.2005.01.001.

[7] M. Shimizu, H. Yano, S. Nagashima, N. Murayama, J. Zhang, J.R. Cashman, H. Yamazaki, Effect of genetic variants of the human flavin-containing monooxygenase 3 on $\mathrm{N}$ - and S-oxygenation activities, Drug Metabolism and Disposition. 35 (2007) 328-330. https://doi.org/10.1124/dmd.106.013094.

[8] H. Yamazaki, M. Shimizu, Survey of variants of human flavin-containing monooxygenase 3 (FMO3) and their drug oxidation activities, Biochemical Pharmacology. 85 (2013) 1588-1593. https://doi.org/10.1016/j.bcp.2013.03.020.

[9] M. Shimizu, A. Shiraishi, A. Sato, S. Nagashima, H. Yamazaki, Potential for drug interactions mediated by polymorphic flavin-containing monooxygenase 3 in human livers, Drug Metabolism and Pharmacokinetics. 30 (2015) 70-74. https://doi.org/10.1016/j.dmpk.2014.09.008.

[10] G. Catucci, C.L. Gao, S.J. Sadeghi, G. Gilardi, Chemical applications of Class B flavoprotein monooxygenases, Rendiconti Lincei-Scienze Fisiche E Naturali. 28 (2017) 195-206. https://doi.org/10.1007/s12210-016-0583-x.

[11] G. Catucci, I. Polignano, D. Cusumano, C. Medana, G. Gilardi, S.J. Sadeghi, Identification of human flavincontaining monooxygenase 3 substrates by a colorimetric screening assay, Analytical Biochemistry. 522 (2017) 46-52. https://doi.org/10.1016/j.ab.2017.01.024.

[12] G. Catucci, C. Gao, G. Rampolla, G. Gilardi, S.J. Sadeghi, Uncoupled human flavin-containing monooxygenase 3 releases superoxide radical in addition to hydrogen peroxide, Free Radic. Biol. Med. 145 (2019) 250-255. https://doi.org/10.1016/j.freeradbiomed.2019.09.038.

[13] J.R. Cashman, B.R. Akerman, S.M. Forrest, E.P. Treacy, Population-specific polymorphisms of the human FMO3 gene: Significance for detoxication, Drug Metabolism and Disposition. 28 (2000) 169-173.

[14] M.A. Hamman, B.D. Haehner-Daniels, S.A. Wrighton, A.E. Rettie, S.D. Hall, Stereoselective sulfoxidation of sulindac sulfide by flavin-containing monooxygenases - Comparison of human liver and kidney microsomes and mammalian enzymes, Biochemical Pharmacology. 60 (2000) 7-17. https://doi.org/10.1016/s0006-2952(00)00301-4.

[15] J.R. Cashman, J. Zhang, J. Leushner, A. Braun, Population distribution of human flavin-containing monooxygenase form 3: Gene polymorphisms, Drug Metabolism and Disposition. 29 (2001) 1629-1637.

[16] J.R. Cashman, J. Zhang, Interindividual differences of human flavin-containing monooxygenase 3: Genetic polymorphisms and functional variation, Drug Metabolism and Disposition. 30 (2002) 1043-1052. https://doi.org/10.1124/dmd.30.10.1043. 
[17] J.R. Cashman, J. Zhang, Human flavin-containing monooxygenases, Annual Review of Pharmacology and Toxicology. 46 (2006) 65-100. https://doi.org/10.1146/annurev.pharmtox.46.120604.141043.

[18] G. Catucci, G. Gilardi, S.J. Sadeghi, Production of drug metabolites by human FMO3 in Escherichia coli, Microb Cell Fact. 19 (2020) 74. https://doi.org/10.1186/s12934-020-01332-1.

[19] L.H. Overby, G.C. Carver, R.M. Philpot, Quantitation and kinetic properties of hepatic microsomal and recombinant flavin-containing monooxygenases 3 and 5 from humans, Chemico-Biological Interactions. 106 (1997) 29-45. https://doi.org/10.1016/s0009-2797(97)00055-0.

[20] S.B. Koukouritaki, M.T. Poch, M.C. Henderson, L.K. Siddens, S.K. Krueger, J.E. VanDyke, D.E. Williams, N.M. Pajewski, T. Wang, R.N. Hines, Identification and functional analysis of common human flavincontaining monooxygenase 3 genetic variants, Journal of Pharmacology and Experimental Therapeutics. 320 (2007) 266-273. https://doi.org/10.1124/jpet.106.112268.

[21] G. Catucci, A. Occhipinti, M. Maffei, G. Gilardi, S.J. Sadeghi, Effect of Human Flavin-Containing Monooxygenase 3 Polymorphism on the Metabolism of Aurora Kinase Inhibitors, International Journal of Molecular Sciences. 14 (2013) 2707-2716. https://doi.org/10.3390/ijms14022707.

[22] S. Castrignano, S. Bortolussi, G. Catucci, O. Gholami, F. Valetti, G. Gilardi, S.J. Sadeghi, Bioelectrochemical profiling of two common polymorphic variants of human $\mathrm{FMO} 3$ in presence of graphene oxide, Electrochimica Acta. 228 (2017) 611-618. https://doi.org/10.1016/j.electacta.2017.01.131.

[23] T.S. Bryant, P. Duggal, B. Yu, A.C. Morrison, T. Shafi, G. Ehret, N. Franceschini, E. Boerwinkle, J. Coresh, A. Tin, Association of FMO3 Variants with Blood Pressure in the Atherosclerosis Risk in Communities Study, International Journal of Hypertension. (2019). https://doi.org/10.1155/2019/2137629.

[24] E.P. Treacy, B.R. Akerman, L.M.L. Chow, R. Youil, C. Bibeau, J. Lin, A.G. Bruce, M. Knight, D.M. Danks, J.R. Cashman, S.M. Forrest, Mutations of the flavin-containing monooxygenase gene (FMO3) cause trimethylaminuria, a defect in detoxication, Human Molecular Genetics. 7 (1998) 839-845. https://doi.org/10.1093/hmg/7.5.839.

[25] G. Catucci, S. Bortolussi, G. Rampolla, D. Cusumano, G. Gilardi, S.J. Sadeghi, Flavin-Containing Monooxygenase 3 Polymorphic Variants Significantly Affect Clearance of Tamoxifen and Clomiphene, Basic Clin. Pharmacol. Toxicol. 123 (2018) 687-691. https://doi.org/10.1111/bcpt.13089.

[26] H.I. Woo, S.K. Lee, J. Kim, S.W. Kim, J. Yu, S.Y. Bae, J.E. Lee, S.J. Nam, S.-Y. Lee, Variations in plasma concentrations of tamoxifen metabolites and the effects of genetic polymorphisms on tamoxifen metabolism in Korean patients with breast cancer, Oncotarget. 8 (2017). https://doi.org/10.18632/oncotarget.22220.

[27] T. Yamada, Y. Mino, T. Naito, J. Kawakami, Impact of flavin-containing monooxygenase 3 and CYP2C19 genotypes on plasma disposition and adverse effects of voriconazole administered orally in immunocompromised patients, Journal of Infection and Chemotherapy. 25 (2019) 1019-1025. https://doi.org/10.1016/j.jiac.2019.05.032.

[28] J.W. Sung, H. Yun, S. Park, Y.J. Kim, J. Yee, K.E. Lee, B. Song, J.E. Chung, H.S. Gwak, Population Pharmacokinetics of Sulindac and Genetic Polymorphisms of FMO3 and AOX1 in Women with Preterm Labor, Pharm Res. 37 (2020) 44. https://doi.org/10.1007/s11095-020-2765-6.

[29] C.L. Gao, G. Catucci, S. Castrignano, G. Gilardi, S.J. Sadeghi, Inactivation mechanism of N61S mutant of human FMO3 towards trimethylamine, Scientific Reports. 7 (2017). https://doi.org/10.1038/s41598-01715224-9.

[30] G. Catucci, G. Querio, S.J. Sadeghi, G. Gilardi, R. Levi, Enzymatically Produced Trimethylamine N-Oxide: Conserving It or Eliminating It, Catalysts. 9 (2019) 1028. https://doi.org/10.3390/catal9121028.

[31] J. Miao, A.V. Ling, P.V. Manthena, M.E. Gearing, M.J. Graham, R.M. Crooke, K.J. Croce, R.M. Esquejo, C.B. Clish, D. Vicent, S.B. Biddinger, G. Morbid Obesity Study, Flavin-containing monooxygenase 3 as a potential player in diabetes-associated atherosclerosis, Nature Communications. 6 (2015). https://doi.org/10.1038/ncomms7498.

[32] S. Chen, A. Henderson, M.C. Petriello, K.A. Romano, M. Gearing, J. Miao, M. Schell, W.J. SandovalEspinola, J. Tao, B. Sha, M. Graham, R. Crooke, A. Kleinridders, E.P. Balskus, F.E. Rey, A.J. Morris, S.B. 
Biddinger, Trimethylamine N-Oxide Binds and Activates PERK to Promote Metabolic Dysfunction, Cell Metabolism. 30 (2019) 1141-1151.e5. https://doi.org/10.1016/j.cmet.2019.08.021.

[33] D.H. Lang, C.K. Yeung, R.M. Peter, C. Ibarra, R. Gasser, K. Itagaki, R.M. Philpot, A.E. Rettie, Isoform specificity of trimethylamine $\mathrm{N}$-oxygenation by human flavin containing monooxygenase (FMO) and P450 enzymes - Selective catalysis by FMO3, Biochemical Pharmacology. 56 (1998) 1005-1012. https://doi.org/10.1016/s0006-2952(98)00218-4.

[34] J.R. Cashman, Y.N. Xiong, L.F. Xu, A. Janowsky, N-oxygenation of amphetamine and methamphetamine by the human flavin-containing monooxygenase (Form 3): Role in bioactivation and detoxication, Journal of Pharmacology and Experimental Therapeutics. 288 (1999) 1251-1260.

[35] R.R. Reddy, E.C. Ralph, M.S. Motika, J. Zhang, J.R. Cashman, Characterization of Human Flavin-Containing Monooxygenase (FMO) 3 and FMO5 Expressed as Maltose-Binding Protein Fusions, Drug Metabolism and Disposition. 38 (2010) 2239-2245. https://doi.org/10.1124/dmd.110.033639.

[36] T. Borbas, J. Zhang, M.A. Cerny, I. Liko, J.R. Cashman, Investigation of structure and function of a catalytically efficient variant of the human flavin-containing monooxygenase form 3, Drug Metabolism and Disposition. 34 (2006) 1995-2002. https://doi.org/10.1124/dmd.106.010827.

[37] C.L. Gao, G. Catucci, G. Di Nardo, G. Gilardi, S.J. Sadeghi, Human flavin-containing monooxygenase 3: Structural mapping of gene polymorphisms and insights into molecular basis of drug binding, Gene. 593 (2016) 91-99. https://doi.org/10.1016/j.gene.2016.08.020.

[38] A. Brunelle, Y.A. Bi, J. Lin, B. Russell, L. Luy, C. Berkman, J. Cashman, Characterization of two human flavincontaining monooxygenase (form 3 ) enzymes expressed in Escherichia coli as maltose binding protein fusions, Drug Metabolism and Disposition. 25 (1997) 1001-1007.

[39] V.E.V. Ferrero, G. Di Nardo, G. Catucci, S.J. Sadeghi, G. Gilardi, Fluorescence detection of ligand binding to labeled cytochrome P450 BM3, Dalton Transactions. 41 (2012) 2018-2025. https://doi.org/10.1039/c1dt11437a.

[40] G. Di Nardo, G. Cimicata, R. Baravalle, V. Dell'Angelo, A. Ciaramella, G. Catucci, P. Ugliengo, G. Gilardi, Working at the membrane interface: Ligand-induced changes in dynamic conformation and oligomeric structure in human aromatase, Biotechnology and Applied Biochemistry. 65 (2018) 46-53. https://doi.org/10.1002/bab.1613.

[41] G. Bruylants, J. Wouters, C. Michaux, Differential scanning calorimetry in life science: Thermodynamics, stability, molecular recognition and application in drug design, Current Medicinal Chemistry. 12 (2005) 2011-2020. https://doi.org/10.2174/0929867054546564.

[42] C.M. Johnson, Differential scanning calorimetry as a tool for protein folding and stability, Archives of Biochemistry and Biophysics. 531 (2013) 100-109. https://doi.org/10.1016/j.abb.2012.09.008.

[43] G. Catucci, S.J. Sadeghi, G. Gilardi, A direct time-based ITC approach for substrate turnover measurements demonstrated on human FMO3, Chemical Communications. 55 (2019) 6217-6220. https://doi.org/10.1039/c9cc01356c.

[44] G. Catucci, G. Gilardi, L. Jeuken, S.J. Sadeghi, In vitro drug metabolism by C-terminally truncated human flavin-containing monooxygenase 3, Biochemical Pharmacology. 83 (2012) 551-8. https://doi.org/10.1016/j.bcp.2011.11.029.

[45] A. Ciaramella, G. Catucci, G. Di Nardo, S.J. Sadeghi, G. Gilardi, Peroxide-driven catalysis of the heme domain of A. radioresistens cytochrome $\mathrm{P} 450116 \mathrm{~B} 5$ for sustainable aromatic rings oxidation and drug metabolites production, N Biotechnol. 54 (2020) 71-79. https://doi.org/10.1016/j.nbt.2019.08.005.

[46] J.M. Sanchezruiz, J.L. Lopezlacomba, M. Cortijo, P.L. Mateo, Differential scanning calorimetry of the irreversible thermal-denaturation of thermolysin, Biochemistry. 27 (1988) 1648-1652. https://doi.org/10.1021/bi00405a039.

[47] J.S. Multani, L.E. Mortenson, Circular dichroism spectra of hydrogenase from Clostridium pasteurianum W 5, Biochimica et Biophysica Acta. 256 (1972) 66-70. https://doi.org/10.1016/0005-2728(72)90163-6.

[48] S.M. Kelly, T.J. Jess, N.C. Price, How to study proteins by circular dichroism, Biochimica Et Biophysica ActaProteins and Proteomics. 1751 (2005) 119-139. https://doi.org/10.1016/j.bbapap.2005.06.005. 
[49] C. Gao, G. Catucci, G. Gilardi, S.J. Sadeghi, Binding of methimazole and NADP(H) to human FMO3: In vitro and in silico studies, International Journal of Biological Macromolecules. 118 (2018) 460-468. https://doi.org/10.1016/j.ijbiomac.2018.06.104.

[50] A. Canciani, G. Catucci, F. Forneris, Structural characterization of the third scavenger receptor cysteinerich domain of murine neurotrypsin, Protein Science. 28 (2019) 746-755. https://doi.org/10.1002/pro.3587.

[51] G. Catucci, I. Zgrablic, F. Lanciani, F. Valetti, D. Minerdi, D.P. Ballou, G. Gilardi, S.J. Sadeghi, Characterization of a new Baeyer-Villiger monooxygenase and conversion to a solely N-or S-oxidizing enzyme by a single R292 mutation, Biochimica Et Biophysica Acta-Proteins and Proteomics. 1864 (2016) 1177-1187. https://doi.org/10.1016/j.bbapap.2016.06.010.

[52] P.L. Privalov, S.A. Potekhin, Scanning microcalorimetry in studying temperature-induced changes in proteins, Methods in Enzymology. 131 (1986) 4-51.

[53] S. Eswaramoorthy, J.B. Bonanno, S.K. Burley, S. Swaminathan, Mechanism of action of a flavin-containing monooxygenase, Proceedings of the National Academy of Sciences of the United States of America. 103 (2006) 9832-9837. https://doi.org/10.1073/pnas.0602398103.

[54] A. Alfieri, E. Malito, R. Orru, M.W. Fraaije, A. Mattevi, Revealing the moonlighting role of NADP in the structure of a flavin-containing monooxygenase, Proceedings of the National Academy of Sciences of the United States of America. 105 (2008) 6572-6577. https://doi.org/10.1073/pnas.0800859105.

[55] C.K. Yeung, E.T. Adman, A.E. Rettie, Functional characterization of genetic variants of human FMO3 associated with trimethylaminuria, Archives of Biochemistry and Biophysics. 464 (2007) 251-259. https://doi.org/10.1016/j.abb.2007.04.014.

[56] R. Orru, D.E.T. Pazmino, M.W. Fraaije, A. Mattevi, Joint Functions of Protein Residues and NADP(H) in Oxygen Activation by Flavin-containing Monooxygenase, Journal of Biological Chemistry. 285 (2010) 35021-35028. https://doi.org/10.1074/jbc.M110.161372.

[57] C.A. Haynes, W. Norde, STRUCTURES AND STABILITIES OF ADSORBED PROTEINS, Journal of Colloid and Interface Science. 169 (1995) 313-328. https://doi.org/10.1006/jcis.1995.1039.

[58] M. Weijers, P.A. Barneveld, M.A.C. Stuart, R.W. Visschers, Heat-induced denaturation and aggregation of ovalbumin at neutral pH described by irreversible first-order kinetics, Protein Science. 12 (2003) 26932703. https://doi.org/10.1110/ps.03242803.

[59] D.M. Ziegler, Recent studies on the structure and function of multisubstrate flavin-containing monooxygenases, Annual Review of Pharmacology and Toxicology. 33 (1993) 179-199. https://doi.org/10.1146/annurev.pharmtox.33.1.179.

[60] L.L. Poulsen, D.M. Ziegler, Multisubstrate flavin-containing monooxygenases - applications of mechanism to specificity, Chemico-Biological Interactions. 96 (1995) 57-73. https://doi.org/10.1016/00092797(94)03583-t.

[61] D.M. Ziegler, An overview of the mechanism, substrate specificities, and structure of FMOs, Drug Metabolism Reviews. 34 (2002) 503-511. https://doi.org/10.1081/dmr-120005650.

[62] A.W.P. Vermeer, W. Norde, The thermal stability of immunoglobulin: Unfolding and aggregation of a multi-domain protein, Biophysical Journal. 78 (2000) 394-404. 
Table 1 Melting temperatures in the presence of excess NADP ${ }^{+}$calculated by CD signal at $222 \mathrm{~nm}$

\begin{tabular}{|l|l|l|l|l|}
\hline & $\mathbf{W T} /{ }^{\circ} \mathbf{C}$ & $\mathbf{V 2 5 7 M} /{ }^{\circ} \mathbf{C}$ & $\mathbf{E 1 5 8 K} /{ }^{\circ} \mathbf{C}$ & E308G $/{ }^{\circ} \mathbf{C}$ \\
\hline No ligand & $45.8 \pm 0.04^{*}$ & $47.8 \pm 0.04$ & $46.2 \pm 0.02$ & $46.2 \pm 0.04$ \\
\hline NADP $^{+}(\mathbf{0 . 5 m M )}$ & $50.6 \pm 0.17^{*}$ & $49.8 \pm 0.04$ & $50.6 \pm 0.04$ & $46.4 \pm 0.03$ \\
\hline
\end{tabular}

*[29] 


\section{Captions to figures}

Fig. 1 DSC thermograms of A) WT, B) V257M, C) E158K, and D) E308G hFMO3 at different scan rates. Proteins concentrations $10 \mu \mathrm{M}$ in $50 \mathrm{mM} \mathrm{KPi} \mathrm{pH} \mathrm{7.4.} \mathrm{Scan} \mathrm{rates} \mathrm{ranged} \mathrm{from} 180^{\circ} \mathrm{C} / \mathrm{h}$. to $18^{\circ} \mathrm{C} / \mathrm{h}$.

Fig. 2 Deconvolution of the DSC thermograms of A) WT, B) V257M, C) E158K D) E308G hFMO3 at a scan rate of $60{ }^{\circ} \mathbf{C} / \mathbf{h}$. Experimental thermograms are shown in black, the derived peak 1 and 2 are in blue and green respectively and their deconvolution in red.

Fig. 3 Melting temperatures and enthalpies calculated from deconvoluted DSC thermograms of A) WT, B) V257M, C) E158K D) E308G hFMO3 at scan rates between $180^{\circ} \mathrm{C} / \mathrm{h}$ and $18^{\circ} \mathrm{C} / \mathrm{h}$. Melting temperatures and enthalpies are shown in red and yellow for peak 1, blue and green for peak 2.

Fig. 4 Effect of NADP ${ }^{+}$on the DSC thermograms of hFMO3. DSC thermograms of A) WT*, B) V257M, C) E158K, D) E308G polymorphic variants in the absence (black) and in presence (red) of 0.5 $\mathrm{mM} \mathrm{NADP}^{+}$. Analysis was performed using $10 \mu \mathrm{M}$ enzyme in $50 \mathrm{mM} \mathrm{KPi}$ buffer $\mathrm{pH}$ 7.4. *[29]

Fig. 5 Isothermal titration calorimetry of NADP' in hFMO3. A) V257M, B) E158K, C) E308G. Titrations were performed at $25^{\circ} \mathrm{C}$ in $50 \mathrm{mM} \mathrm{KPi}$ buffer at $\mathrm{pH}$ 7.4. D) Thermodynamics parameters $(\Delta \mathrm{G}$, $\Delta \mathrm{H}$ and $-\mathrm{T} \Delta \mathrm{S}$ ) of NADP+ binding for $\mathrm{WT} *$, V257M and E158K hFMO3. *[29]

Fig. 6 CD signal of hFMO3 at $222 \mathrm{~nm}$ as function of temperature. Curves for V257M (A) diamonds, E158K (B) triangles and E308G (C) squares fitted by black solid lines compared to that of WT in grey circles fitted by grey dashed lines. 
Fig. 7 Effect of NADP ${ }^{+}$on CD signal of hFMO3 at $222 \mathrm{~nm}$ as function o temperature for WT and polymorphic mutants of hFMO3. Histograms represent the change in ellipticity at each measured temperature that was observed upon addition of NADP+ for WT (A) V257M (B), E158K (C) and E308G (D). 


\section{Figures}

Figure 1

A

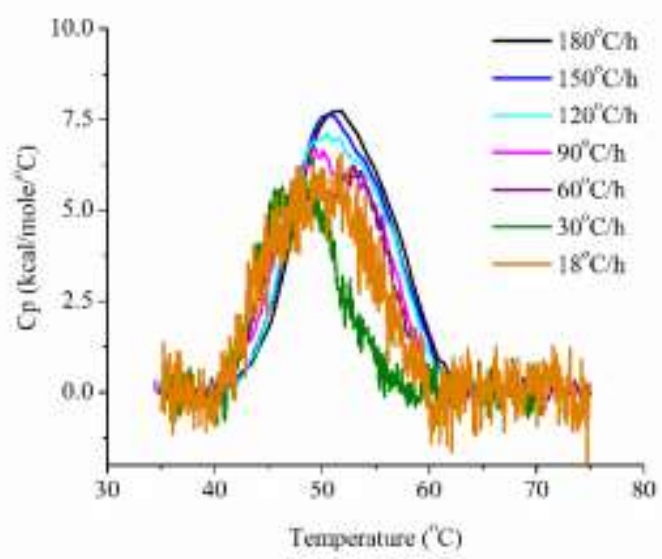

C

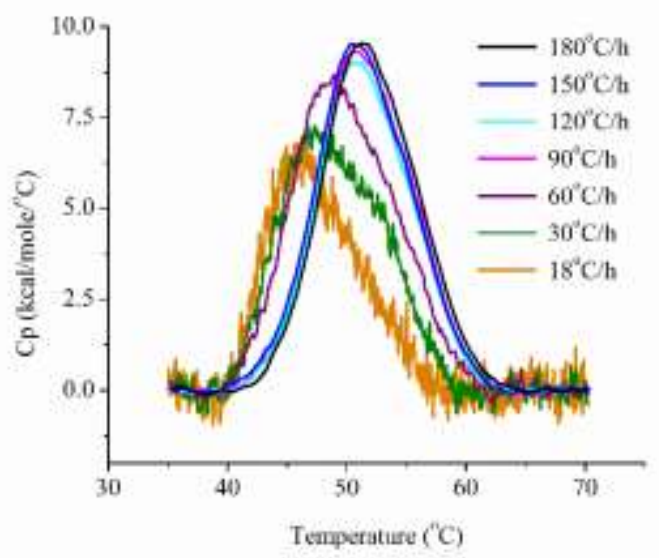

B

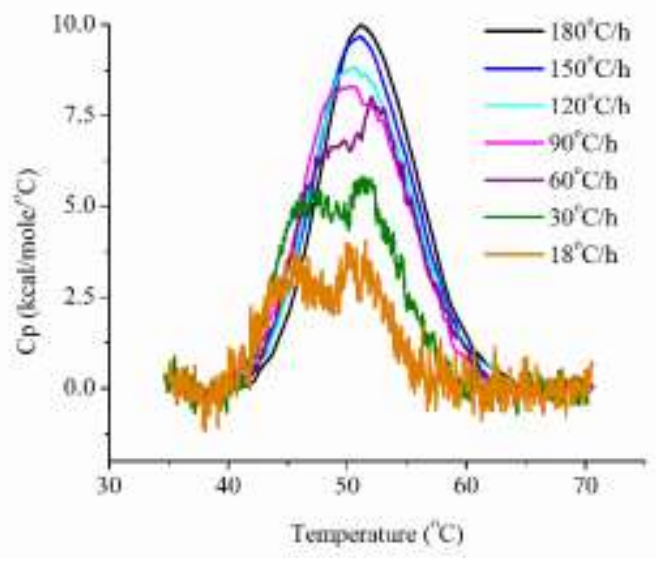

D

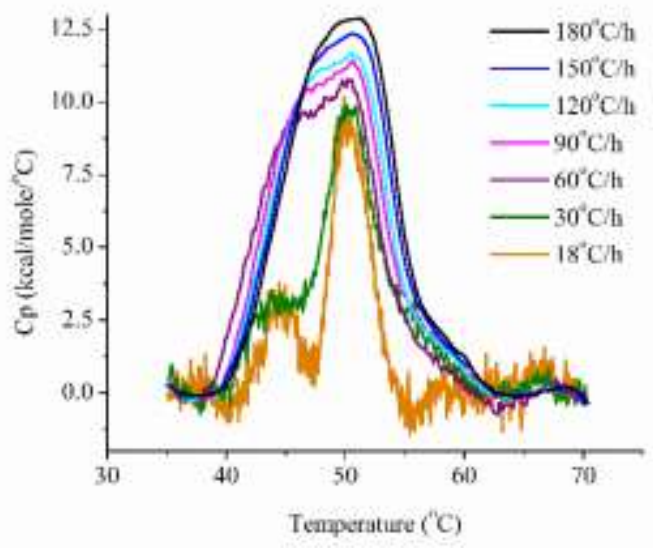


Figure 2

A

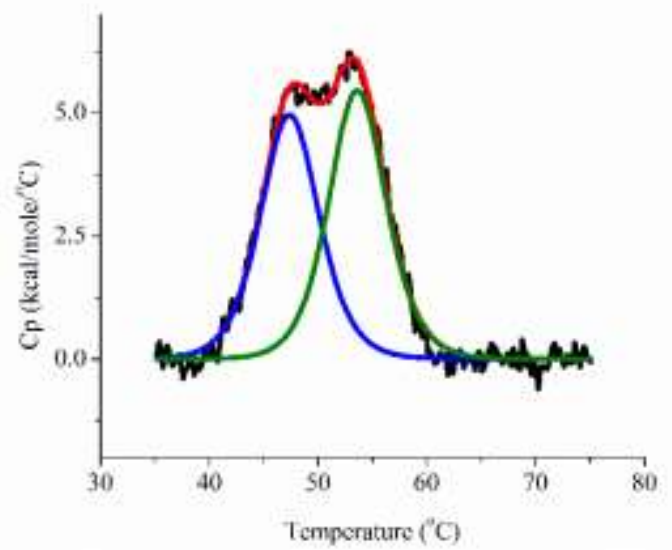

C

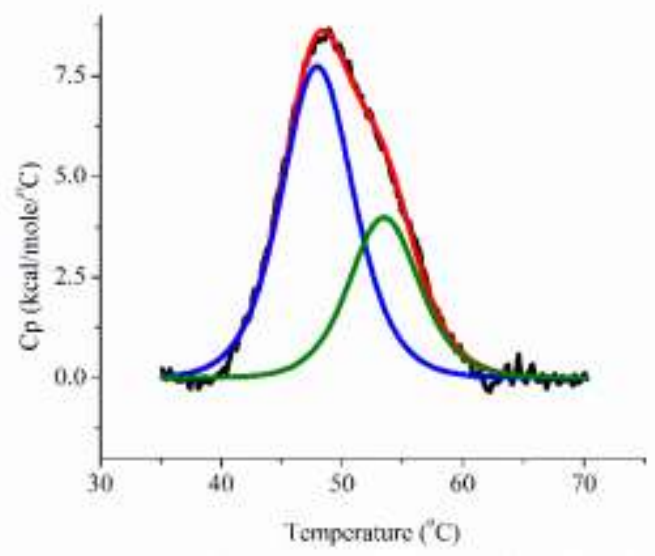

B

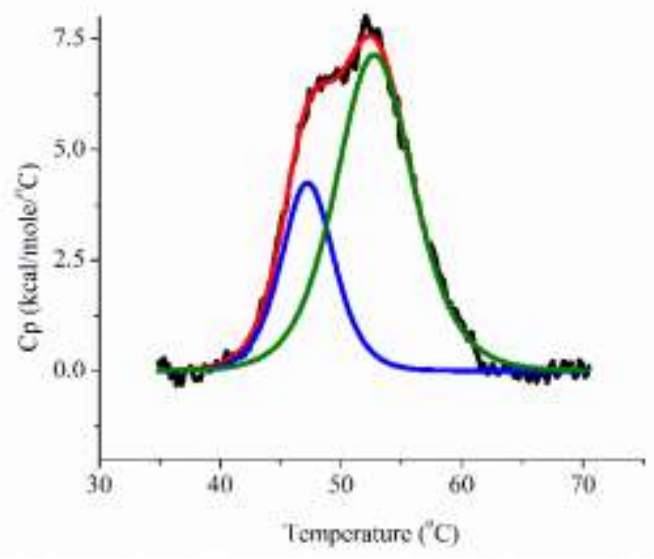

D

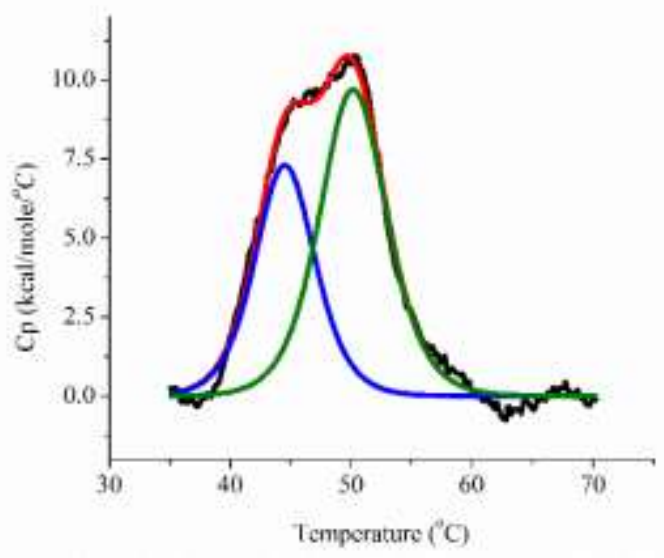


Figure 3
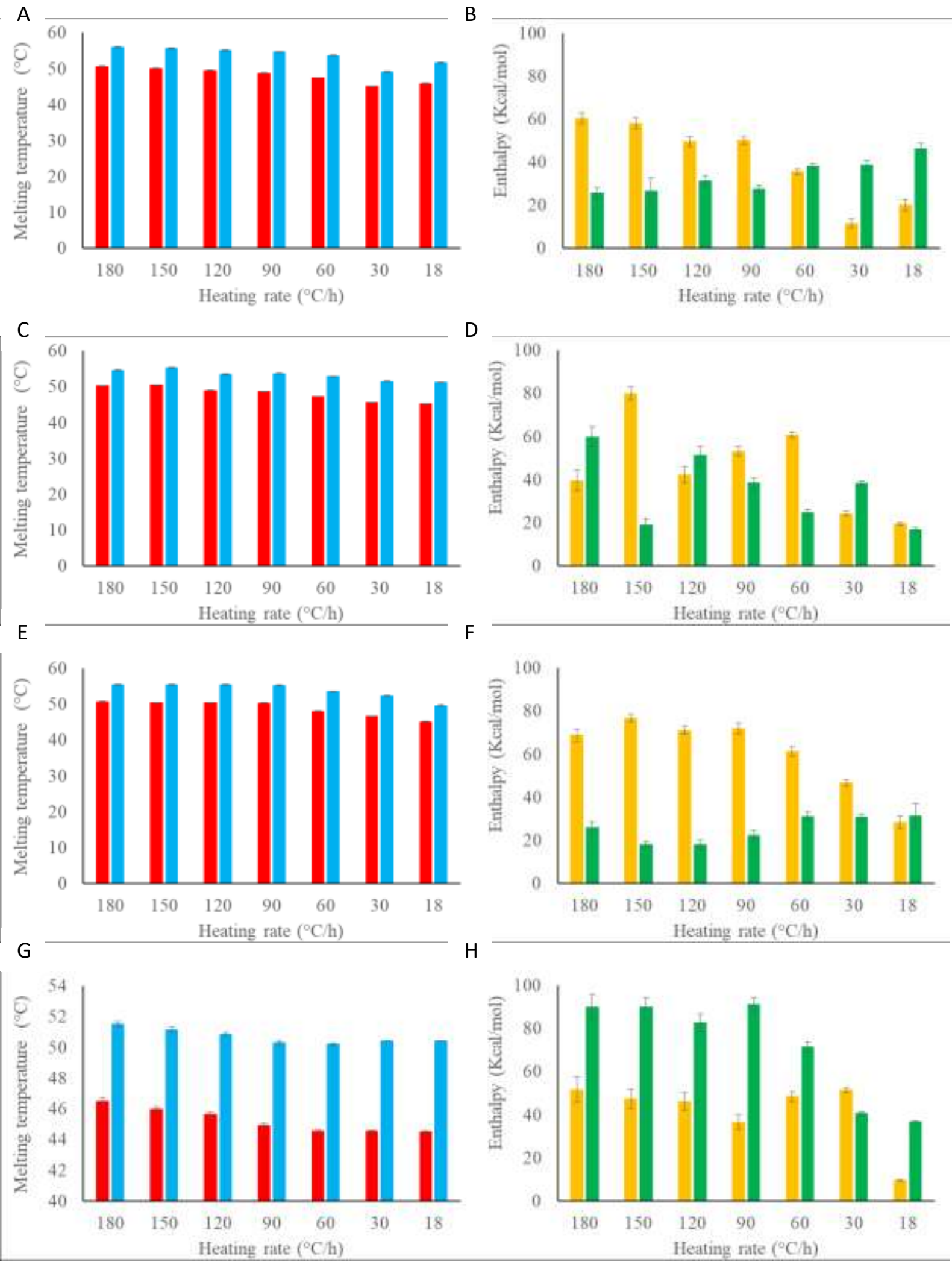
Figure 4

A

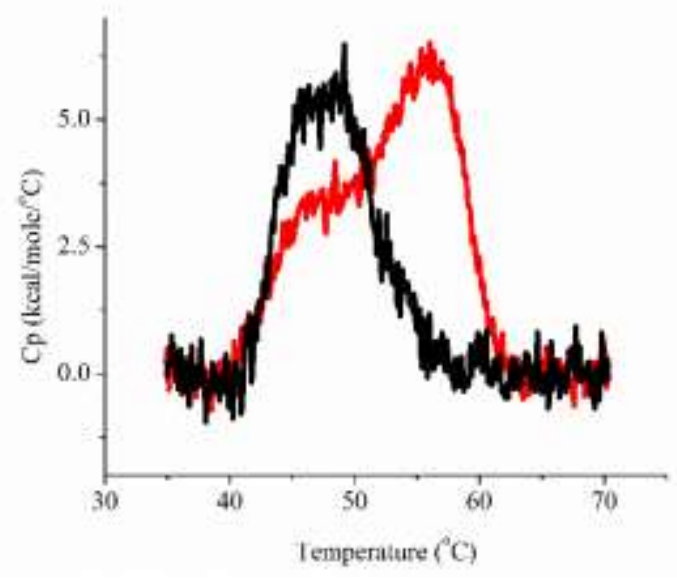

C

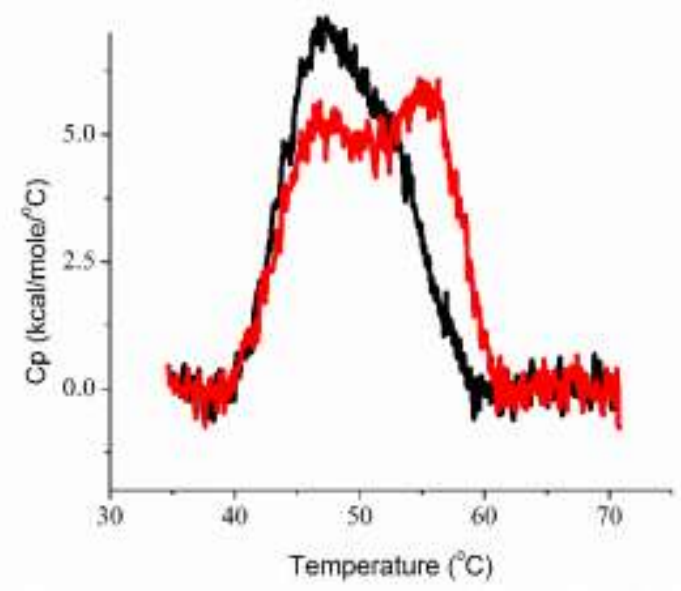

B

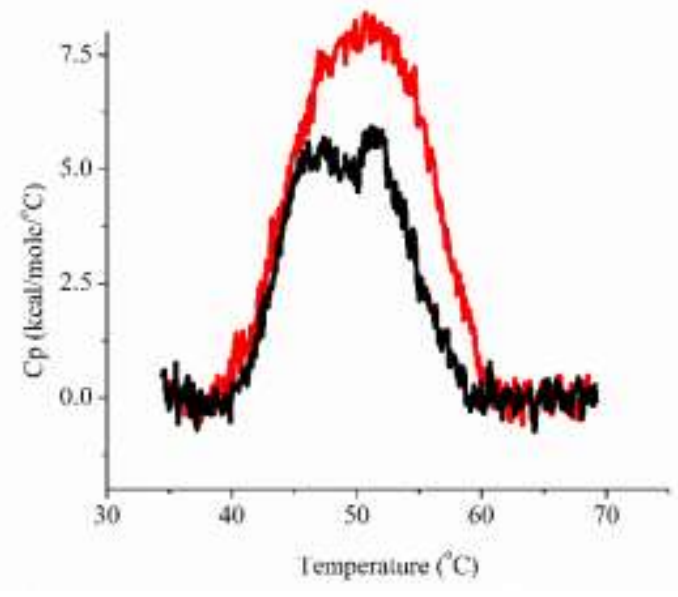

D

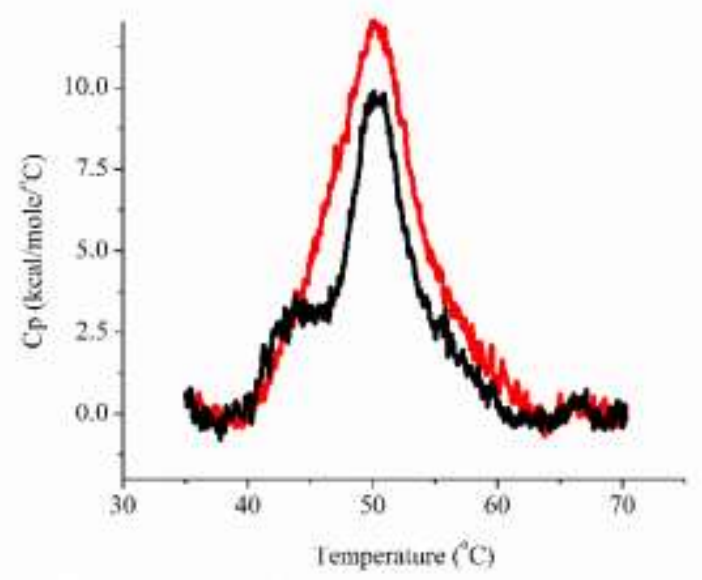


Figure 5

A

B

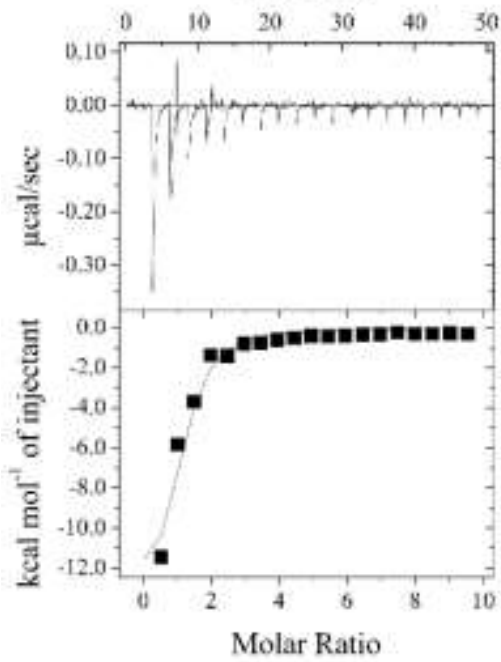

D

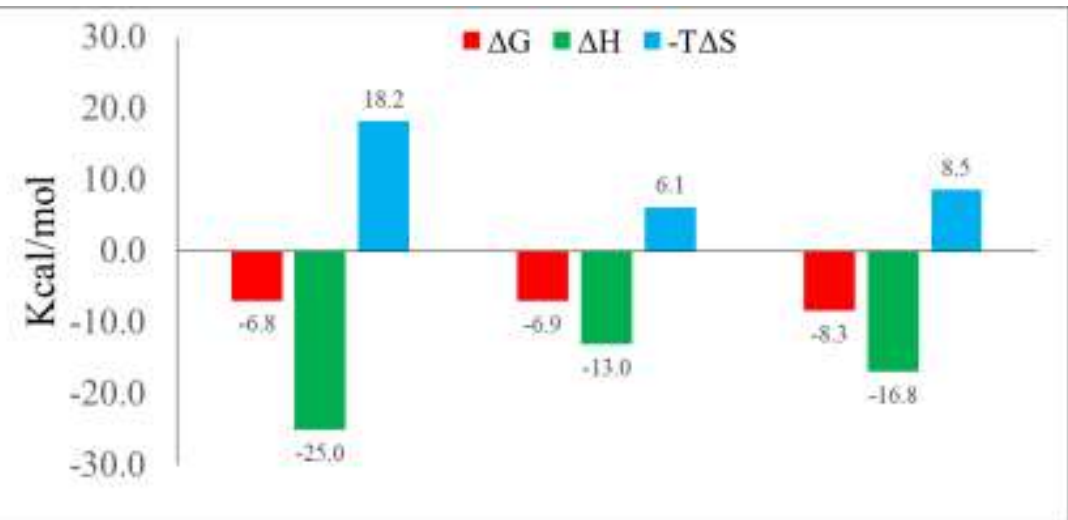

Time (min)

C
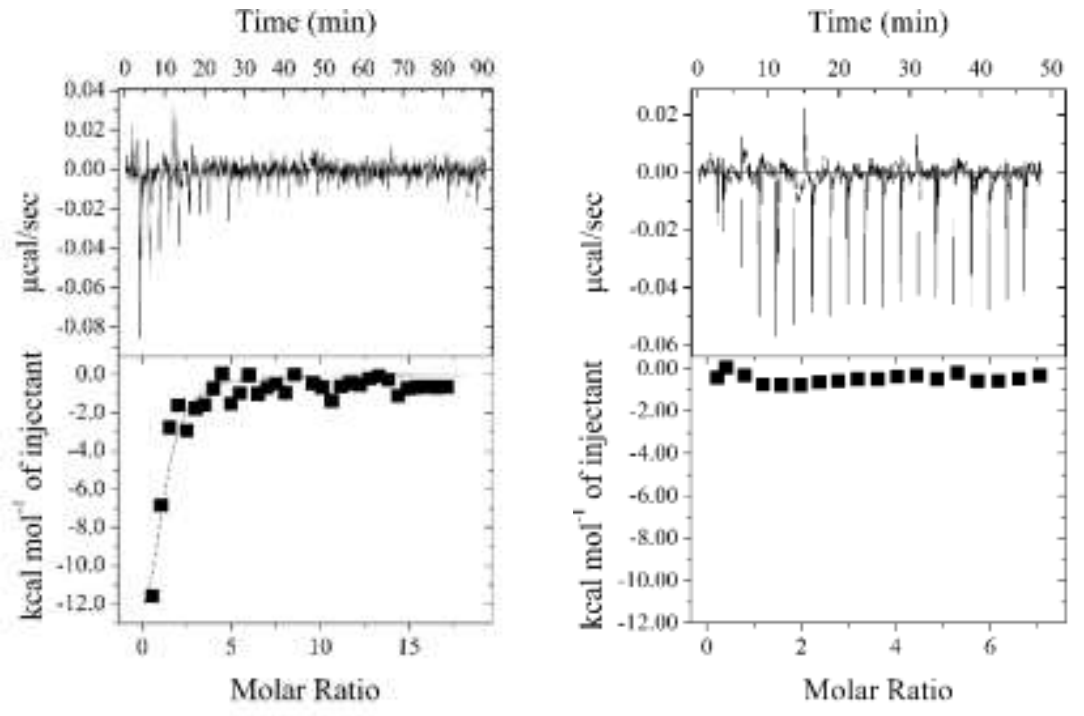
Figure 6

A

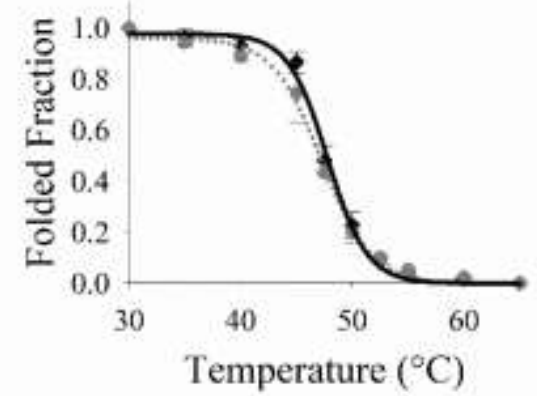

B

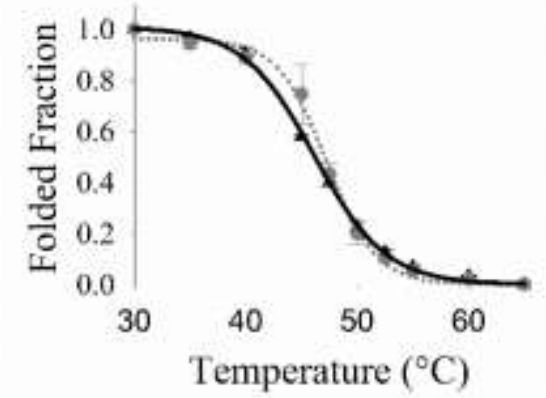

C

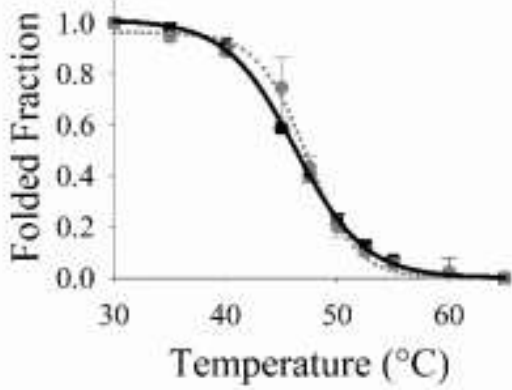


Figure 7

A

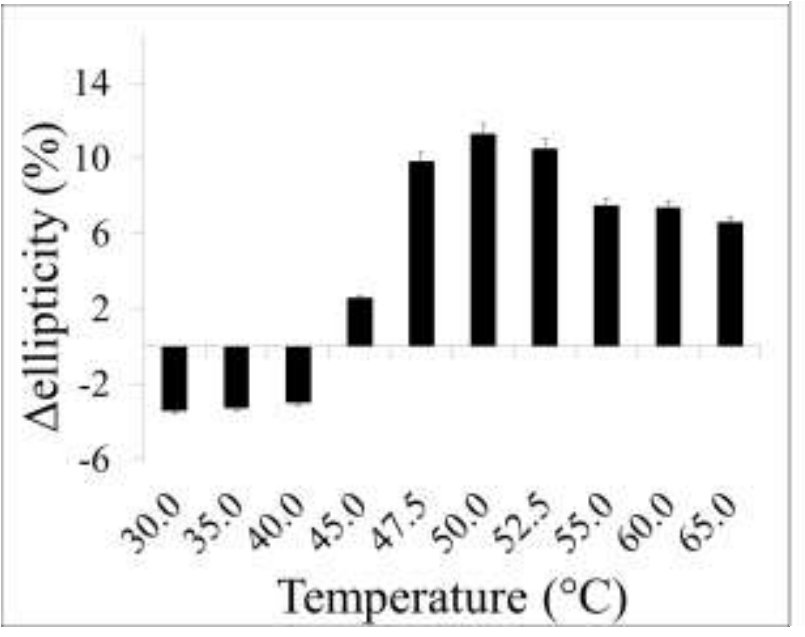

C

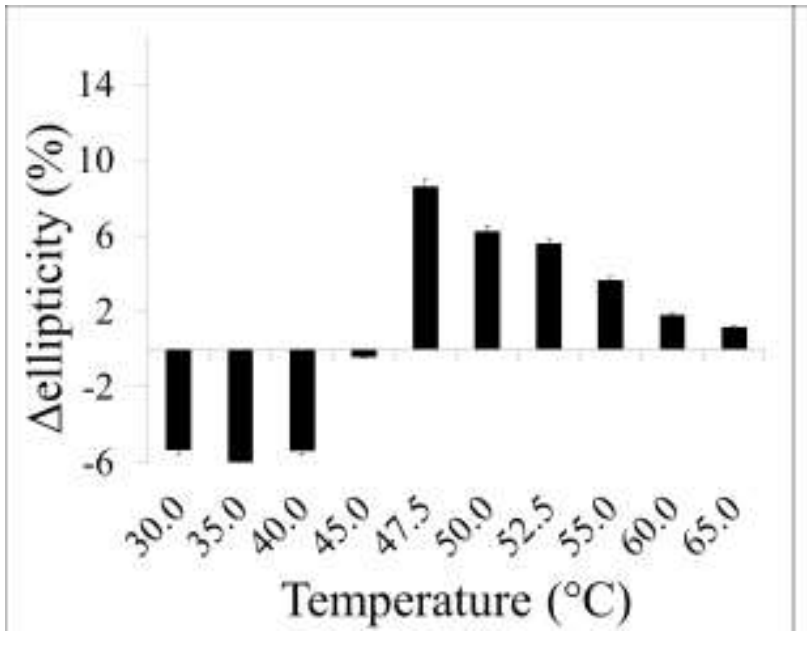

B

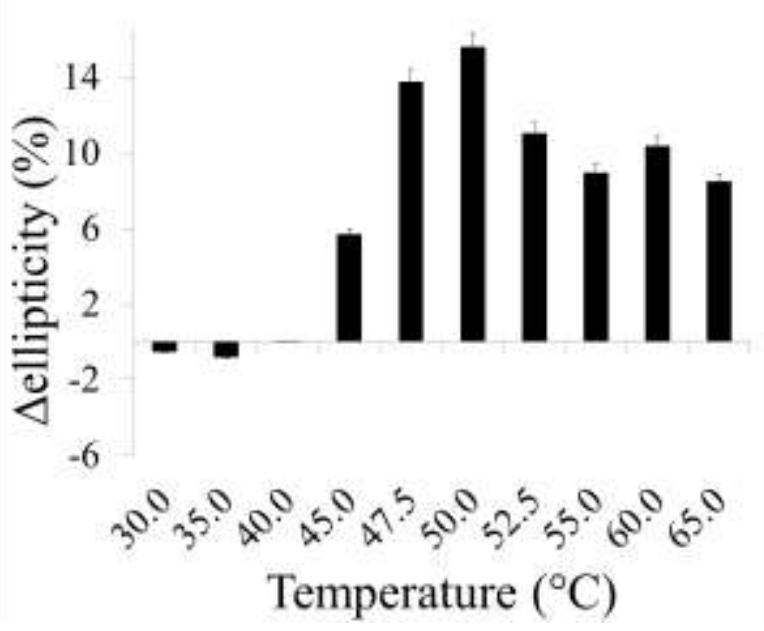

D

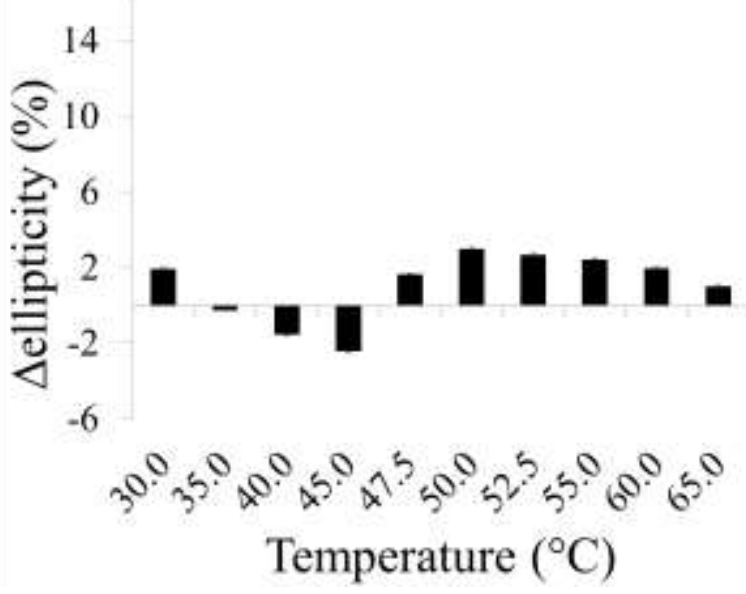

